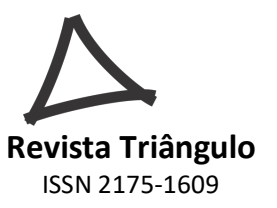

\title{
A RELAÇÃO DE ESTUDANTES COM A ESCOLHA DO TEMA PARA SEUS PROJETOS DE PESQUISA: MOBILIZAÇÃO E SENTIDO PARA PESQUISAR
}

\author{
THE RELATIONSHIP BETWEEN STUDENTS AND THE CHOICE OF THEME FOR \\ RESEARCH PROJECTS: MOBILIZATION AND SENSE TO SEARCH
}

\author{
LA RELACIÓN DE ESTUDIANTES CON LA ELECCIÓN DEL TEMA PARA SUS \\ PROYECTOS DE INVESTIGACIÓN: MOVILIZACIÓN Y SENTIDO PARA INVESTIGAR
}

Uly Alves Moreira

E-mail: ulyalves@hotmail.com

Messias Dieb

E-mail: mhdieb@gmail.com

Universidade Federal do Ceará - UFC

\begin{abstract}
RESUMO
O presente trabalho tem como objetivo categorizar os móbeis que impulsionam a escolha dos temas dos projetos de pesquisa elaborados por equipes que cursaram a disciplina de Metodologia Cientifica no semestre 2017.1, do curso de Pedagogia - noturno, da Universidade Federal do Ceará (UFC). Para tratar sobre este assunto, fizemos uso da conceituação de Charlot (2000) sobre móbeis, mobilização e sentido. Trata-se de uma pesquisa quantiqualitativa, na qual se utilizou como instrumento de construção de dados um questionário com questões objetivas e subjetivas. Após serem estudados e analisados os dados, sua análise aponta como resultados os principais móbeis que se sintetizam em três grandes tipologias: 1) o desejo de conhecer melhor o tema, 2) a relação entre o trabalho do estudante e o tema e 3) a relação entre vivências e/ou situações de cunho pessoal dos estudantes e o tema. Neste sentido, conclui-se que esses móbeis que impulsionaram os indivíduos na escolha do tema estão muito vinculados às suas histórias de vida e experiências particulares, sobre as quais os estudantes desejam trazer para a discussão e/ou conhecer mais aspectos ligados aos temas.
\end{abstract}

PALAVRAS-CHAVE: Educação. Estudantes universitários. Disciplinas eletivas.

\begin{abstract}
This article has as a goal to identify the mobilization that drives the choice of the themes for research projects developed by the teams that attended the discipline of Scientific Methodology in the semester 2017.1, in Teacher Education Program (Pedagogy) from the Federal University of Ceará. We used the conceptualization of Charlot (2000) about mobilization and sense. It is a quantitative-qualitative research, in which a questionnaire with objective and subjective questions was used as a data-building tool. After the data have been studied and analyzed, the analysis points out as results the main mobiles that are synthesized in three large typologies: 1) The desire of knowing better the theme, 2) the relationship between the job of the student and the theme and 3) the relationship between experiences and/or situations of student's personal matter and the theme. In this sense, it is concluded that the mobilization that has driven individuals in the theme choice is linked to their lifehistories and private experiences, on which students want to bring to the discussion and/or know more aspects related to the themes.
\end{abstract}

KEYWORDS: Education. University students. Elective courses.

\section{RESUMEN}

El presente trabajo tiene como objetivo categorizar los motivantes que impulsaron la selección de los temas de los proyectos de investigación elaborados por los equipos que cursaron la consigna Metodología Cientifica en el semestre 2017.1 del curso de Pedagogía - nocturno, de la Universidad Federal de Ceará. Para tratar sobre ese asunto, utilizamos la conceptualización de Charlot (2000) sobre mobilización y sentido. Se trata de una investigación cuantitativa y cualitativa, en la cual se utilizó como instrumento de construcción de datos un cuestionario con preguntas objetivas y subjetivas. Después de ser estudiados y analizados los datos, el análisis

\begin{tabular}{l|l|l|l|l|l|l} 
(C) Rev. Triang. & Uberaba, MG & v. 11 & n.3 & p. $116-128$ & Set. / Dez. & 2018
\end{tabular}


señaliza como resultados los principales elementos mobilización que se resumen en tres grandes tipologías: 1) el deseo de conocer mejor el tema, 2) la relación entre el empleo del estudiante y el tema y 3) la relación entre vivencias y / o situaciones de naturaleza personal entre los estudiantes y el tema. En este sentido, se concluye que los elementos de mobilización que impulsaron a los individuos en la selección del tema están fuertemente vinculados a sus historias de vida y experiencias particulares; es precisamente a partir de ese vínculo que los estudiantes desean traer a discusión y conocer más aspectos relacionados a los temas en cuestión.

PALABRAS-CLAVE: Educación. Estudiante universitario. Disciplina electiva.

\section{INTRODUÇÃO}

Ao ingressar no curso de Pedagogia da Faculdade de Educação da Universidade Federal do Ceará (FACED/UFC), os alunos se matriculam na disciplina de Metodologia Científica, que é obrigatória no primeiro semestre e busca fornecer algumas das ferramentas científicas necessárias para o desenvolvimento de seus estudos na Universidade. É no decorrer dessa disciplina que se aprende como planejar e elaborar um projeto de pesquisa como um dos requisitos para aprovação na disciplina. Com base nas experiências vivenciadas pelos estudantes em relação à escolha do tema para o projeto de pesquisa, vimos a necessidade de analisar como se dá essa seleção de tema do projeto de pesquisa entre os membros da equipe que o elabora e, mais precisamente, o que os mobiliza para isso.

Para tratar acerca do conceito de mobilização, trazemos as ideias de Charlot (2000), as quais compreendem o fato de que a mobilização se dá por meio da ideia de movimento interno do sujeito e que mobilizar-se é algo que o impulsiona de dentro para fora, diferentemente de motivar-se, que é algo que vem de fora, ou seja, que precisa de uma força exterior que faça o sujeito seguir agindo. Partindo dessa ideia, buscamos refletir sobre: o que mobiliza os estudantes em sua escolha? $\mathrm{O}$ que possibilita que tal escolha estabeleça algum sentido para esses sujeitos? Quais foram os principais móbeis que impulsionaram a escolha final do tema para o projeto? Essas, portanto, são as questões que nortearam a pesquisa que ora apresentamos neste artigo. Como objetivo, buscamos categorizar os móbeis que impulsionaram a escolha dos temas dos projetos de pesquisa que foram elaborados pelas equipes de estudantes que cursaram a disciplina de Metodologia Científica, ofertada pelo curso de Pedagogia Noturno da FACED/UFC, mais precisamente no semestre 2017.1, no qual participamos, respectivamente enquanto autores deste texto, como bolsista de iniciação a docência (Bolsista PID) e professor da disciplina. Trata-se, pois, de uma pesquisa quantiqualitativa, na qual utilizamos como instrumento de construção de dados um questionário, 
com questões objetivas e subjetivas. Após serem estudados e analisados os dados, buscamos categorizar os móbeis que foram indicados por meio da análise do conteúdo.

\section{REFERENCIAL TEÓRICO}

O conceito de móbil implica uma razão ou motivo para o agir, como, por exemplo, o que leva o indivíduo a prosseguir em suas escolhas. Para isso, esse sujeito precisa engajar-se em uma atividade que, para ele, contemple boas razões para fazê-la (CHARLOT, 2000). Segundo este autor, o móbil só pode ser definido por referência a uma atividade, já que é o desejo em realizar a atividade que irá impulsionar esse indivíduo a concluir ou continuar realizando determinada ação para alcançar sua meta. Assim, a atividade é outro conceito trabalhado por Charlot (2000), o qual não podemos deixar de lado, visto que está diretamente correlacionada ao móbil, sendo, pois, a atividade um conjunto de ações propulsionadas por um móbil e que visam a uma meta. As ações, por sua vez, são operações implementadas durante a atividade, ou seja, são as atitudes tomadas pelo indivíduo para realizar determinada atividade.

No que diz respeito à meta, esta representa o objetivo a ser alcançado. Com isso, para distinguir o móbil e a meta, o autor rememora que o móbil é o desejo de alcançar a meta (resultado) para si satisfazer e dar um sentido para desencadear a atividade. Então, no nosso caso, temos a escolha do tema como sendo a atividade, a qual gerará um conjunto de ações que levará à escrita de um projeto de pesquisa. A meta ou objetivo dessa atividade é ter um tema, um assunto a ser pesquisado e o que queremos saber são as razões/motivos que levaram à escolha deste tema.

Charlot (2000), tomando por base os estudos de Leontiev, explica o conceito de sentido. Para ele, o sentido de uma atividade é a relação entre sua meta e seu móbil, entre o que incita a agir e o que orienta a ação, como resultado imediatamente buscado. Dessa forma, temos que a escolha do tema do projeto de pesquisa (atividade), que é o primeiro passo para escrever um projeto de pesquisa sobre um determinado tema (meta), permitirá que o indivíduo satisfaça um desejo, que é o móbil, ou seja, encontrar esse tema. Diante disso, ao direcionarmos nosso olhar para a mobilização da escolha do tema no desenvolvimento do projeto de pesquisa, trazemos também o conceito de sujeito, utilizado por Charlot (2000), como um ser humano, um ser social e um ser singular em ação no mundo. Notamos que, 
levando em consideração esses aspectos, o sujeito se manifesta no mundo e para o mundo, tentando dar um sentido a este. Assim, vão surgindo os móbeis que incitarão o sujeito a realizar ações que o levarão a atingir suas metas.

\section{MATERIAIS E MÉTODOS}

Nesta pesquisa, procuramos abordar a questão de maneira quanti-qualitativamente para alcançar o nosso objetivo. Desta forma, salientamos que a abordagem quantitativa se caracteriza por empregar a quantificação, tanto nas modalidades de coleta de informação quanto no tratamento dos dados, mediante procedimentos estatísticos. Já a pesquisa qualitativa se preocupa com o aprofundamento da compreensão de um grupo social, de uma organização, entre outros (GERHARDT, 2009). Nesse sentido, fizemos uso das duas abordagens, sendo a quantitativa para mensurar a nossa amostra e a frequência das respostas mais comuns do questionário e a qualitativa para compreensão dos conteúdos e temas abordados na escrita dos respondentes.

Quanto aos procedimentos, iniciamos com um aprofundamento das leituras da bibliografia a fim de conhecer as diferentes contribuições científicas sobre o assunto que se pretendeu estudar. Trata-se, portanto, do primeiro passo em qualquer tipo de pesquisa (GONÇALVES, 2005). Já o procedimento e instrumento de coleta de dados utilizado foi o questionário, o qual tem muitas vantagens. Essas vantagens são traduzidas no fato de o questionário poder representar um instrumento de rápida aplicação em termos de tempo, apresentando baixo custo e permitindo atingir uma grande população dispersa, dando maior liberdade e tempo para o respondente com a possibilidade de termos menores distorções. Dessa forma, distribuímos os questionários impressos para todos os alunos que estavam matriculados na disciplina de Metodologia Cientifica em 2017.1 do curso de Pedagogia da UFC.

Tivemos uma amostra de 34 participantes, os quais responderam a 12 questões subjetivas e 2 objetivas sobre a questão da escolha dos temas para seus projetos de pesquisa. As perguntas visaram ainda a caracterização dos sujeitos, por compreendermos que a individualidade afeta as escolhas de cada um, além de questões diretamente relacionadas ao objetivo deste artigo, a exemplo das mobilizações e dos sentidos particularizados, para que pudéssemos obter mais clareza em relação aos resultados. Conforme a explicação de Gerhardt 
(2009), há duas possibilidades de análise de dados de pesquisa qualitativa: análise de conteúdo e análise de discurso. Para analisarmos os móbeis que impulsionaram a escolha dos temas dos projetos de pesquisa, elaborados pelas equipes de estudantes que cursavam a disciplina de Metodologia Científica, utilizamos a análise de conteúdo. Assim sendo, por meio da análise de conteúdo, visamos a obter, por procedimentos sistemáticos e objetivos de descrição do conteúdo das mensagens, indicadores (quantitativos ou não) que permitissem a inferência de conhecimentos relativos às condições de produção e recepção das mensagens que eles nos passaram por meio dos questionários (GERHARDT, 2009).

Esse procedimento foi dividido em 3 etapas, como propõe Campos (2004). A primeira foi a fase de pré-exploração dos questionários, na qual analisamos todos eles para apreender de uma forma global as ideias principais e os seus significados gerais. A segunda foi a seleção das unidades de análise, a qual consistiu em expressões e termos ligados às respostas que estavam diretamente ligados ao objetivo do artigo. Por fim, ocorreu o processo de categorização, no qual foram agrupadas as unidades de análise, em especial relativas às mobilizações e sentidos para a escolha dos temas. Neste caso, ocorreu uma categorização não apriorística, pois consistiu na criação das categorias a partir do contexto das respostas dos indivíduos. O critério utilizado para o agrupamento das unidades de análise em categorias partiu do frequenciamento dos móbeis e sentidos, o que consistiu na repetição dos conteúdos comuns à maioria dos respondentes. Por questões éticas, as informações sobre os entrevistados serão dadas por nomes fictícios.

\section{ANÁLISE DOS DADOS E RESULTADOS}

Dos 34 integrantes da turma de Metodologia Científica que responderam ao questionário, 28 são do sexo feminino e apenas 6 do sexo masculino. Assim temos $82,3 \%$ do nosso público do sexo feminino. A faixa etária dos participantes está entre 18 e 50 anos, sendo que 8 desses integrantes têm 18 anos e estão cursando pela primeira vez o ensino superior, ou seja, estão no primeiro semestre do curso de Pedagogia, recém-saídos do ensino médio. Outro aspecto importante é que 58,8\% dos entrevistados têm entre 18 e 21 anos, enquanto os outros $41,2 \%$ possuem entre 22 e 50 anos de idade.

Quanto ao grau de escolarização, 44,1\% dos sujeitos já haviam iniciado outra graduação e não concluíram, sendo, dentre os cursos citados, administração, design de moda, 
direito, farmácia, filosofia e pedagogia em faculdade da rede particular. Os demais 45,9\% estão ingressando pela primeira vez no ensino superior. Além disso, 79,4\% da turma estava cursando o primeiro semestre de Pedagogia noturno, enquanto os demais estudantes da turma estavam em semestre variados, sendo 3 alunos do curso de História. Após serem estudados e analisados os dados, esta análise apontou como resultados que os principais móbeis para a escolha do tema de seus projetos de pesquisa são: 1) o desejo de conhecer melhor o tema, 2) a relação entre o trabalho do estudante e o tema da pesquisa e 3) a relação entre vivências e/ou situações de cunho pessoal dos estudantes e o tema a ser estudado. Esses móbeis foram essenciais para o reconhecimento do tema pelas equipes como sendo relevante de ser investigado.

\subsection{O desejo de conhecer melhor o tema}

Um dos móbeis mais recorrentes nas respostas foi o desejo de conhecer melhor o tema escolhido. Esse desejo nos sujeitos existe por muitas razões, desde a vontade de se aprofundar no tema até a curiosidade em saber sobre o assunto, como podemos notar na fala de Bia (nome fictício) quando questionada sobre o motivo de ter sugerido determinado assunto e seu desejo por estudá-lo.

Educação especial me chama muita atenção a área e também como um motivo para se aprofundar mais no assunto. [...] Pois o conhecimento da vivencia e de como acontece desperta muita curiosidade e questionamentos. Um conhecimento maior para futuramente pesquisar na área ou até mesmo fazer uma especialização. (Bia)

Como podemos notar nessa fala, a área da Educação Especial, que foi o tema escolhido para o projeto de pesquisa de sua equipe, foi a que lhe chamou atenção. Percebemos, também, em seu discurso, que o desejo em aprofundar o tema visa a adquirir mais conhecimentos sobre esse assunto. Afinal, como afirma Charlot (2000), ao nos apropriarmos de um saber, criamos uma forma de relação com o mundo na qual nos sentimos mais inteligentes, ou seja, desenvolvemos uma relação de identidade com o saber e, por isso, o desejamos.

Outro ponto importante, citado em sua fala, é a vivência com o tema, o que nos faz inferir que essa aluna deve ter contato frequente com pessoas que possuem necessidades especiais e isso gera curiosidades e questionamentos que precisam ser melhor estudados. Bia espera que, por meio dos estudos realizados sobre o tema, ela possa compreender melhor o 
tema, tanto para que responda a suas perguntas como talvez para conviver com pessoas que possuem alguma deficiência, entendendo como é o mundo para elas e do que precisam.

Bia parece afirmar que esses conhecimentos, os quais ela irá adquirir com o desenvolvimento do projeto, serão úteis também dentro da academia. Essas informações lhe servirão para incrementar outras pesquisas no futuro, mas também poderão ser benéficas ao pensar em progredir na vida acadêmica, pois ela poderá se utilizar do que aprendeu sobre esse tema para o ingresso em uma especialização (pós-graduação lato sensu). Além desse aspecto levantado por Bia, a estudante Dani afirma que desejou que o assunto escolhido, a partir do tema para o desenvolvimento do projeto de pesquisa, fosse agradável de ser estudado.

Nesse sentido, o que a motivou a optar foi o fato de ter considerado "um tema que seja prazeroso e que possibilite o conhecimento daquela área para os integrantes". Assim sendo, vimos que, para ela, o tema não tem apenas a função de auxiliar na integração de conhecimentos do curso de Pedagogia, mas que comporte uma dimensão prazerosa. Para que isso ocorra, deve ser um tema que encante a todos do grupo e provoque nos alunos uma satisfação em estudar o assunto. Esse desejo de conhecer o tema também se revelou mediante afirmações de que deveria ser um tema realmente relevante para eles.

Em alguns questionários, havia respostas como: “a concepção de relevância prática do assunto", "a relevância do tema e a vontade de pesquisar sobre o tema", ou ainda, "ter relevância para nossa vida profissional". Percebemos que todos esses indivíduos desejam adquirir mais conhecimento na área, visando à importância do tema na vida pessoa, mas também profissional e acadêmica. Em suma, eles necessitam reconhecer uma aplicação prática para o tema, para prosseguir com os estudos sobre o assunto.

Outros sujeitos desejaram conhecer melhor o tema, com o discurso de que é interessante e que, estudando sobre o assunto, possam se tornar bons profissionais nessa área. Dessa forma, temos algumas repostas com o discurso parecido ao de Maria, no qual ela afirma que:

[...] aborda uma temática interessante e será muito importante conhecer um pouco mais sobre educação inclusiva. [...] poder me preparar melhor e me tornar uma boa profissional que saiba lidar com crianças sem deficiência e também com crianças portadoras de necessidades especiais. (Maria). 
Conhecer a temática abordada é, portanto, um aspecto de suma importância que aparece na fala da Maria, mas, para além desse aspecto, ela também almeja o melhor para o seu futuro profissional. Isso é frisado principalmente sobre o aspecto relativo a sua área de formação: a Pedagogia. Assim como apareceu em outros discursos, o fato de a temática ser interessante tem a ver com sua utilização prática também e, por isso, é que pode mobilizar o indivíduo a estudar sobre o assunto.

O móbil que percebemos aqui é que o desejo pelo assunto a ser estudado se mostra essencialmente vinculado a construção de um saber a ser posto em funcionamento em suas práticas profissionais. Diante disso, podemos entender que o que dá sentido para esses indivíduos desejarem conhecer melhor sobre o tema é a sua exploração para adquirir não apenas mais conhecimentos sobre o assunto, mas que dê prazer e que permita aguçar a curiosidade. Notamos ainda que existe uma preocupação no coletivo em possibilitar o conhecimento para todos, já que o desenvolvimento do trabalho foi em grupo. Essa é uma reflexão que não podemos deixar de fazer, pois esse móbil envolve muito mais que apenas o desejo de conhecer melhor o tema.

Esses indivíduos não visam ao conhecimento pelo conhecimento, mas, sim, como uma forma de ajudar os outros, de melhorar suas futuras práticas profissionais e de seguir carreira acadêmica. Contudo, também está atrelado ao fato de que eles podem melhorar sua convivência em espaços que lhes permitam aplicar esses conhecimentos adquiridos a partir do estudo desenvolvido sobre o tema. Por tudo que foi exposto, podemos compreender que o envolvimento desses sujeitos com o tema do projeto de pesquisa está voltado para a sua melhor compreensão, de forma que tal conhecimento adquirido lhes proporcione uma sensação de desejo realizado.

\subsection{A relação entre o trabalho do estudante e o tema}

A prática no trabalho também foi citada como um dos motivos para se estudar o tema proposto. Isso é o que foi ressaltado nesta fala de Murilo: "sou professor e a questão da existência de alunos com necessidades de atendimentos especiais está na minha realidade”. Assim sendo, compreendemos que essa realidade está presente em alguns discursos, pois a pesquisa foi realizada com alunos do turno noturno e esses indivíduos, em sua maioria, já 
trabalham na área de educação e os demais em outras áreas. Os que trabalham na área da educação já desenvolvem atividades em escolas, dentro e fora de sala de aula, tanto como professores como auxiliares ou estagiários. Eles veem a necessidade da aplicabilidade do saber construído na pesquisa sendo ainda maior do que quando questionados sobre o desejo de conhecer sobre o tema. Como já vivem no mundo do trabalho e já lidam com muitas situações que exigem mais conhecimento técnico e científico, eles afirmam em suas justificativas de escolha a utilidade prática que o tema deve ter.

Assim, a importância ou o sentido que eles dão ao tema está diretamente relacionado com o que motivou essa escolha: para que influencie positivamente em sua prática no trabalho, como verificamos na fala da Dani quando diz: “[...] É um tema muito abrangente. Além disso, eu trabalho na área da educação infantil e fundamental, por isso, me identifiquei. [...] Identificar aspectos pesquisados nesse tema no meu cotidiano, algo que seja somado a minha formação". O tema do projeto de pesquisa elaborado por Dani e sua equipe foi a “Educação Infantill". Como podemos notar em sua fala, ela trabalha na área e busca com o conhecimento adquirido com esse tema aplicar novas ações/didáticas em suas práticas pedagógicas, bem como melhorar sua performance no trabalho. Assim, ela deseja relacionar o que está pesquisando com a prática, para resolver uma problemática que esteja vivenciando no momento.

Em um outro discurso, também verificamos como outra aluna espera que a pesquisa a ajude em seu trabalho.

Escolhemos devido a eu trabalhar na Educação Infantil e já vivenciar a prática. [...] A busca por maior conhecimento para poder contribuir no direito das crianças a Educação de qualidade. [...] ter uma primeira visão de como fazer um projeto que pode me ajudar na pratica na creche onde trabalho. (Mariana).

Quando questionada sobre o porquê deseja estudar o tema da educação infantil, ela revela que já trabalha na área e acrescenta a sua preocupação com a educação das crianças na sociedade atual, visando a uma educação de qualidade. A explicação para essas relações entre o trabalho dos estudantes e o tema pode ser encontrada em Charlot (2000) quando afirma que o sentido que atribuímos ao que temos para aprender tem sua tessitura delineada por meio dos laços familiares e também de todas as relações interpessoais que construímos, seja na escola seja no trabalho. 
Para Mariana, os conhecimentos construídos a partir de seus estudos sobre o tema devem influenciar diretamente em suas vivências dentro da escola. Nesse sentido, compreendemos que os estudantes trabalhadores utilizam seu trabalho como um móbil para a escolha do tema do projeto de pesquisa, tendo o desejo de que os conhecimentos construídos com o desenvolvimento desse projeto lhes proporcionem uma melhor desenvoltura no trabalho. Isso se explica, pois, para eles, esses estudos precisam ser aplicados em seu dia a dia, justificando realmente a necessidade de estudá-los e de adquirir mais informações.

\subsection{A relação entre vivências e/ou situações de cunho pessoal dos estudantes e o tema}

Notamos que alguns alunos queriam aprender a fazer o projeto de pesquisa, mas sem estar, de fato, interessados em um tema específico. Um exemplo disso foi o da equipe de Lucas, que era um aluno ouvinte. Em sua opinião, a disciplina serviu para aprender a desenvolver um projeto de pesquisa e o tema do projeto era apenas uma consequência desse aprendizado.

Vejo o projeto de pesquisa da disciplina como um recurso para exercitar os conhecimentos aprendidos em sala, portanto não possuo exigências em relação ao tema. Prefiro a harmonia da equipe. O tema proposto também não me é tão alheio, com isso, me senti confortável para trabalhar a partir dele (Lucas).

Observamos que Lucas, apesar de não possuir "exigências em relação ao tema", sentiu-se confortável em estudar o assunto proposto por sua equipe, intitulado "A situação dos estudantes trabalhadores, matriculados no curso de Pedagogia Noturno da FACED-UFC, em relação à atividade de estágio em Educação Infantil”. Nesse sentido, o ponto que chama atenção é a sua preferência pela harmonia da equipe, o que se deve ao fato de que ele não propôs nenhum tema para ser desenvolvido no projeto de pesquisa, aceitando esse tema que foi proposto por outro integrante da equipe.

Outros alunos, como Maria, justificam a escolha do tema por ter contato com o assunto em seu cotidiano e por sentir necessidade em saber mais sobre o tema. Dessa forma, Maria propôs para seu grupo o tema de "Educação Especial”, defendendo o tema dizendo que "sempre estudei com colegas especiais e às vezes me sentia perdida dentro da sala de aula". Como podemos perceber, o sujeito se apropria do mundo em sua lógica de indivíduo, a qual é diferente da lógica do social, muito embora o aspecto social seja também responsável pela constituição da lógica individual. Desse duplo movimento, o que se pode concluir é que a 
construção da história humana se dá em sociedade e essa construção somente é possível porque o homem realiza uma atividade no mundo, a qual se transforma para ele em um desafio fundamental a sua existência (CHARLOT, 2000). Assim sendo, para não se sentir perdida, Maria justifica sua proposição de tema ao grupo a partir de fatos que estão relacionados a sua experiência pessoal de vida.

Do mesmo modo, Sophia, a partir de sua experiência pessoal no âmbito da escola, justifica a escolha do tema que ela propôs a sua equipe: "Evasão escolar no ensino profissionalizante". Segundo ele, "já fui aluna de escola profissionalizante e tive que sair por motivos pessoais e acho interessante abordar e entender o assunto". Notamos, assim, formas de abordar o assunto de cunho mais pessoais, ou seja, situações que foram vivenciadas por essas pessoas e que, a partir dessa experiência, elas viram uma necessidade de estudar o assunto. Portanto, ao engajar-se em uma atividade, como a escolha do tema para os projetos de pesquisa, os estudantes o fizeram porque encontraram "boas razões" para isso, ou seja, o fizeram porque atribuíram um sentido às ações que atenderam a uma necessidade específica (CHARLOT, 2000).

A vivência pessoal dos estudantes se mostrou como um importante elemento de mobilização para os membros da equipe, promovendo as interações necessárias para a realização da atividade. Eles tentam explicar de que forma vivenciaram essas situações, principalmente como alunos em sala de aula, interagindo, a título de exemplo, com pessoas com deficiências ou testemunhando a evasão escolar, inclusive fazendo parte dela. Entendemos, por meio dessas falas, que os estudantes fizeram parte desse contexto social e que, por isso, pretendem se aprofundar com os estudos do tema escolhido no projeto de pesquisa, pois também visam a trazer contribuições para a sociedade a partir de seus estudos. Afinal, os indivíduos constroem sua relação com o mundo ao mesmo tempo em que constroem uma relação consigo mesmo e uma relação com os outros, a qual envolve uma forma de atividade que é compartilhada e valorizada, ao mesmo tempo em que é desejada pelo sujeito (CHARLOT, 2000).

Outra explicação de cunho pessoal foi analisada no discurso de Eloá, a qual vem de seu envolvimento com o assunto que seria abordado no projeto desenvolvido por sua equipe, e que fora proposto por ela mesma. Tal explicação se refere ao processo de "castração" da 
criatividade artística da criança durante o ensino fundamental. A partir desse tema, Eloá revela que seu desejo em estudar esse assunto está em seu "envolvimento com a prática artística" e com algumas experiências de negação por parte da escola acerca do desenvolvimento de suas habilidades artísticas. Assim, podemos compreender que o pesquisador, ainda que aprendiz, como é o caso desses estudantes,

não é um ser humano genérico, mas um ser social [que] faz parte da investigação e leva para ela tudo aquilo que o constitui como um ser concreto em diálogo com o mundo em que vive. Suas [... escolhas] são feitas a partir do lugar sócio-histórico no qual se situa e dependem das relações intersubjetivas que estabelece com os [outros] sujeitos. É nesse sentido que se pode dizer que o pesquisador é um dos principais instrumentos da pesquisa, porque se insere nela (FREITAS, 2002, p. 29).

Portanto, inevitavelmente, todo trabalho de pesquisa, enquanto atividade, impele-nos a construir uma relação com o saber e com o aprender (CHARLOT, 2000), na medida em que, ao definirmos a nossa temática de estudo, precisamos nos mobilizar para gerenciar todas as outras definições e justificativas desse empreendimento, atribuindo-lhe sempre um sentido, um valor.

\section{CONSIDERAÇÕES FINAIS}

A análise de conteúdo dos questionários nos possibilitou uma visão geral sobre o que mobilizou as escolhas dos temas de pesquisas realizadas pela turma de Metodologia Científica, do curso de Pedagogia, do período noturno no semestre 2017.1. Verificamos, nesta pesquisa, três móbeis que perpassaram pela maioria dos questionários, sendo eles o que deram sentido às ações desenvolvidas, a saber: o desejo de conhecer melhor o tema, a relação entre o trabalho do estudante e o tema e, por fim, a relação entre vivências e/ou situações de cunho pessoal dos estudantes e o tema.

Cada um desses móbeis teve a fundamental importância de direcionar as equipes na escolha do tema para o projeto de pesquisa. O primeiro se repetiu em vários discursos com justificativas diferentes, mas nunca deixando o conhecimento sobre o assunto em segundo plano. O segundo móbil está relacionado ao trabalho que o indivíduo desenvolve na área da educação, pois esses sujeitos visam a aplicar os conhecimentos adquiridos, por meio do tema, durante o desenvolvimento do projeto de pesquisa em suas práticas educativas dentro da escola em que trabalham. O terceiro móbil está ligado às vivências que os sujeitos tiveram em sua vida pessoal e que estes julgaram importante em seu cotidiano, um fato que se destacou de 
seu interesse ou que se repetiu com frequência, dando a esses indivíduos um sentido ao estudá-los. Diante disso, concluímos que esses móbeis impulsionaram os indivíduos na escolha do tema e deram um sentido ao projeto de pesquisa para o grupo quando apontam para questões ligadas a expectativas futuras, tanto de trabalho profissional na área da Pedagogia como também de prosseguimento na própria formação, seja em nível de especialização ou de mestrado e doutorado.

\section{REFERENCIAS}

CAMPOS, Claudinei José Gomes. Método de análise de conteúdo: ferramenta para a análise de dados qualitativos no campo da saúde. Revista Brasileira de Enfermagem. Brasília, ano 57, n. 5, p. 611-614, set./out., 2004. Disponível em:

$<$ http://www.scielo.br/pdf/reben/v57n5/a19v57n5>. Acesso em: 12 Jul. 2018.

CHARLOT, Bernard. Da relação com o saber: elementos para uma teoria. Porto Alegre: Artmed, 2000.

FREITAS, Maria Tereza. A abordagem sócio-histórica como orientadora da pesquisa qualitativa. Cadernos de Pesquisa. São Paulo: Fundação Carlos Chagas, n. 116. p. 21-39. Jul. 2002.

GERHARDT, Tatiana Engel. Métodos de pesquisa: planejamento e gestão para o desenvolvimento rural da SEAD/UFRGS. Porto Alegre: Editora da UFRGS, 2009.

GONÇALVES, Hortência de Abreu. Manual de metodologia da pesquisa científica. São Paulo: Avercamp, 2005. 